\title{
On the comparison between the LISFLOOD modelled and the ERS/SCAT derived soil moisture estimates
}

\author{
G. Laguardia and S. Niemeyer \\ European Commission - DG Joint Research Centre, Institute for Environment and Sustainability, Italy \\ Received: 23 April 2008 - Published in Hydrol. Earth Syst. Sci. Discuss.: 3 June 2008 \\ Revised: 25 September 2008 - Accepted: 15 October 2008 - Published: 12 December 2008
}

\begin{abstract}
In order to evaluate the reliability of the soil moisture product obtained by means of the LISFLOOD hydrological model (De Roo et al., 2000), we compare it to soil moisture estimates derived from ERS scatterometer data (Wagner et al., 1999b).

Once evaluated the effect of scale mismatch, we calculate the root mean square error and the correlation between the two soil moisture time series on a pixel basis and we assess the fraction of variance that can be explained by a set of input parameter fields that vary from elevation and soil depth to rainfall statistics and missing or snow covered ERS images.

The two datasets show good agreement over large regions, with $90 \%$ of the area having a positive correlation coefficient and $66 \%$ having a root mean square error minor than $0.5 \mathrm{pF}$ units. Major inconsistencies are located in mountainous regions such as the Alps or Scandinavia where both the methodologies suffer from insufficiently resolved land surface processes at the given spatial resolution, as well as from limited availability of satellite data on the one hand and the uncertainties in meteorological data retrieval on the other hand.
\end{abstract}

\section{Introduction}

Soil moisture is well recognized as a key variable of the hydrological cycle since it exerts an essential control on the water and energy balance, such as the partitioning of precipitation in infiltration and runoff and of the available energy at the land-atmosphere interface into sensible and latent heat fluxes.

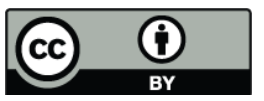

Correspondence to: G. Laguardia (giovanni.laguardia@jrc.it)
It is a variable of great interest for meteorology because it represents the lower boundary condition for meteorological forecast models (see Ferranti and Viterbo, 2006), and it exerts a feedback effect on rainfall especially in continental areas (see Castelli et al., 1996; Alfieri et al., 2008). In hydrology soil moisture is an important term in any water balance determination, and as initial conditions for flood forecasting; at the same time soil moisture serves as a key variable for drought monitoring (see McVicar and Jupp, 1998). In ecology it controls the mixing and competition between different plant species (see Scanlon et al., 2005), and in agriculture soil moisture has a major control on yield, raising the need of controlling irrigation practices (Kite and Droogers, 2000).

When determining soil water content over large areas, it is necessary to balance the requirements of spatial and temporal resolution of the sampling as well as of the accuracy of measurement. The measurement methods can be roughly classified as ground based and remote, and as direct and indirect.

The most accepted method is the gravimetric one. This ground based direct measurement is the standard procedure for soil water determination against which all other methods, including other field measurements such as Time Domain Reflectometry, are calibrated. Since it consists of an instantaneous point measurement, it is not possible to use such method in a long term monitoring campaign. Field methods are generally complex, labour intensive, and expensive. For these reasons the availability of field data is strongly limited to a small number of samples and a short period of data collection even for small catchment areas. Local scale variations in soil properties, terrain, and vegetation cover make the selection of representative points in the field difficult. A number of studies have been conducted to relate point measurements to larger scales by means of geostatistical analysis (Western and Blöschl, 1999), probability density function analysis (Avissar and Pielke, 1989), or fractal analysis

Published by Copernicus Publications on behalf of the European Geosciences Union. 
(Rodriguez-Iturbe et al., 1995). Vachaud et al. (1985) introduced the concept of temporal stability, which has been further exploited by several authors (see, e.g. Grayson and Western, 1998; Martínez-Fernández and Ceballos, 2005; Starks et al., 2006; De Lannoy et al., 2007). However, it is necessary to exploit other methods for applications over large regions.

The main alternatives to direct measurements in the field comprise retrieving soil moisture by satellite observations and estimating soil moisture based on hydrological models.

Remote sensing techniques allow covering large spatial extents at high temporal frequency with uniform measurement. Information retrieved in several regions of the electromagnetic spectrum has been used for the detection of soil moisture.

Most efforts are concentrated on exploiting the potential of direct techniques, which are based on active and passive microwaves methods (e.g. Engman and Chauhan, 1995; Schmugge, 1998). The soil depth which the retrieved soil moisture is referred to is mainly a function of the wavelength of the microwave radiation, but essentially limited to the first $5 \mathrm{~cm}$ of the top-soil layer. Moreover, the data are difficult to interpret due to many confounding factors, such as vegetation characteristics and surface roughness (see Verhoest et al., 2008). The major constraints in the use of those data for operational hydrological applications are related to the shortcomings in the coupling of the spatial resolution and the temporal frequency features: high resolution data are available at low frequencies (e.g. $30 \mathrm{~m}$ resolution, 35 days revisit time for ERS SAR), while high frequency data have low spatial resolution (e.g. $50 \mathrm{~km}$ resolution, 1 day revisit time for NOAA AMSU).

The indirect techniques based on measures in the optical and thermal infrared ranges (e.g. $1.1 \mathrm{~km}$ resolution, 1 day revisit time for NOAA AVHRR) describe the properties of a surface, but not the properties of the soil under the surface. However, these techniques allow for the determination of surface energy fluxes that can be applied in soilvegetation-atmosphere transfer models (e.g. Castelli et al., 1999). A number of approaches have been proposed based on measurements of surface temperature evaluated in the thermal infrared region (e.g. Price, 1980), possibly integrated by vegetation information retrieved in the visible channels (e.g. Carlson et al., 1995; Niemeyer, 2000). These methods, mainly built upon AVHRR data, have been transposed to the new generation sensors, such as MODIS (e.g. Nishida et al., 2003) and METEOSAT Second Generation (e.g. Verstraeten et al., 2006), with improved spatial and radiometric resolution. The quantity and quality of ground data requirements as well as the effect of cloud cover limit the applicability of certain techniques in the context of long-term and wide-area studies.

Another alternative is represented by estimating soil moisture based on hydrological or land surface models. Here the spatial and temporal sampling scales become variables to be chosen by the modeller, who has to take into account indeed the availability of information at the chosen scale for a proper parameterization of the model and the constraints related to CPU time. The vertical distribution of soil moisture can be represented by different soil water compartments within the model. In general, distributed hydrological models consider at least the root zone, which is the most important zone in terms of runoff generation and land-atmosphere interaction.

In large scale applications an explicit representation of soil water processes is difficult to be obtained and its parameters to be retrieved, hence a certain degree of generalization and simplification is necessary. Accordingly, most large-scale hydrological or land surface models represent soil moisture as a simplified storage term, and water exchange processes as conceptual relations. The need of input meteorological data often leaves the issues related to network density and reliability and spatial distribution not solved.

Nowadays soil moisture modelling over large scales is a quite spread practice. First of all, it is worth to mention that weather forecast and climatic simulation models always comprise land surface routines for taking into account the exchanges at the ground, i.e. TESSEL (Beljaars and Viterbo, 1999) and NOAH (Ek et al., 2003). Moreover, hydrological models are run over large areas for floods and droughts monitoring, i.e. VIC (Luo and Wood, 2007; see http://hydrology.princeton.edu/ luo/ research/FORECAST/current.php) and LISFLOOD (Thielen et al., 2008; see http://natural-hazards.jrc.ec.europa.eu/ index.html).

For both satellite and model derived soil moisture products it is necessary to perform calibration and validation, in order to understand whether the derived products are able to represent in a reliable way the soil moisture spatial and temporal variability. The validation strategies for both satellite and model derived soil moisture products can be summarized into three main methods, namely the comparison to field data (at-point validation), to aggregate measurements (aggregate/global validation), and to independent spatial products (point-by-point validation).

When comparing to field data, it is possible to benefit from measurements of soil moisture and of water and energy fluxes. In the last years, a great effort of field data collection has been carried out in order to obtain ground truth data for remote sensing products development and to gain a deeper insight into processes (e.g. HAPEX-Sahel, FIFE, SMEX, REMEDHUS, OK Mesonet, SMOS-REX). However, the space and time coverage of such datasets is limited and the data are often not readily available. Moreover, it is necessary to deal with the high spatial variability of soil moisture and the scale mismatch issue.

The aggregate validation approach consists in summarizing the data by means of water balance models for obtaining variables that are currently measured, e.g. river discharge (see Scipal et al., 2005) and atmospheric water vapour fluxes (see Seneviratne et al., 2004; Hirschi et al., 2006). The major weakness of such methods is that the aggregation of the 
information causes the loss of any insight into soil moisture spatial variability. In addition, the over-parameterization of water balance models leaves some degrees of freedom in the calibration, which could result in a poor representation of the processes not involved in the definition of the objective function (see Refsgaard, 2000).

In the comparison to independent spatial products it is possible to have a direct insight into the spatial variability of the processes. The issues related to the mismatch of scales and soil depths have to be considered carefully. It is worth noticing that the independent product itself should have been validated. The evaluation of the agreement of independent soil moisture data should be considered as a preliminary exercise towards the development of data assimilation frameworks.

The main goal of this work is the evaluation of the LISFLOOD (De Roo et al., 2000) soil moisture estimates as produced within the framework of the European Drought Observatory (see http://desert.jrc.it) with respect to independent measurements, namely the ERS scatterometer derived Soil Water Index satellite (Wagner et al., 1999b) within a pointby-point scheme. We investigate the agreement of the two datasets and the factors controlling the differences among them.

In the following we present the two datasets, define the framework of the comparison, and present and discuss the results.

\section{Data}

\subsection{The ERS/SCAT soil water index}

In this chapter, the Global Soil Moisture Archive from ESA ERS Scatterometer Data provided by the Vienna University of Technology (Scipal et al., 2002) is presented.

The soil moisture data of the Global Soil Moisture Archive have been obtained by the scatterometer on board the ERS1 and ERS-2 satellites, operated by the European Space Agency (ESA). The ERS scatterometer operates at $5.3 \mathrm{GHz}$ (C-band) vertical polarization, collecting backscatter measurements over an incidence angle range from $18^{\circ}$ to $59^{\circ}$, using three sideways-looking antennas. The sensor achieves global coverage within 3 to 4 days, when each beam provides measurements of radar backscatter from the sea and land surface for overlapping $50 \mathrm{~km}$ resolution cells, with a $25 \mathrm{~km}$ grid spacing at approximately 10:30 and 22:30 LT for ascending and descending tracks, respectively. Since the scatterometer can not be operated at the same time as the synthetic aperture radar (SAR) mounted on ERS-1 and ERS-2, the temporal sampling rate could be reduced, particularly over Europe where the SAR is often switched on.

Wagner et al. (1999b) proposed a soil moisture retrieval technique based on a change detection approach. Satellite remote sensing is capable of retrieving information only about the soil surface layer. Even though microwaves penetrate the surface layer to a certain extent (depending on the wave- length and soil wetness), the information gained is limited to the topsoil layer. In the case of C-band microwaves, the derived surface soil moisture $m_{s}$ can be referred to a soil depth smaller than $5 \mathrm{~cm}$.

It is well known that the radar signal is sensitive to vegetation, surface roughness, and snow cover. With respect to the two first factors, they are taken into account within the change detection algorithm (Wagner et al., 1999a, b). With respect to snow, unfortunately it is not possible to exclude its observations based solely on scatterometer data (see Scipal et al., 2005), hence it is not possible to exclude erroneous data being still present in the scatterometer database.

The semi-empirical modelling approach developed by Wagner et al. (1999b) uses the information contained in surface soil moisture time series $m_{s}(t)$ to estimate the status of the profile soil moisture content. The method has been derived by considering a two-layer soil model: The first layer corresponds to the remotely sensed surface layer, the second one to the remaining soil depth. Assuming that the water flux between the two layers is proportional to the difference in soil moisture content between the two layers, the following simple water balance equation is used to establish a link between the area-average soil water content in the soil column, $\Theta$, and the soil water content of the remotely sensed surface layer, $\Theta_{s}$ :

$L \frac{d \Theta(t)}{d t}=C \cdot\left[\Theta_{s}(t)-\Theta(t)\right]$,

where $t$ is time, $L$ the depth of the reservoir layer, and $C$ an area-representative pseudo-diffusivity constant. Assuming that $C$ is constant, and setting $T=L / C$, the solution of the differential equation is:

$\Theta(t)=\frac{1}{T} \int_{-\infty}^{t} \Theta_{s}\left(t^{\prime}\right) \exp \left[-\frac{t-t^{\prime}}{T}\right] d t^{\prime}$.

Since the ERS scatterometer provides measurements at irregular time intervals, the continuous formulation of the integral equation is replaced by its discrete analogous:

$\operatorname{SWI}(t)=\frac{\sum_{i} m_{s}\left(t_{i}\right) \exp \left[\frac{t-t_{i}}{T}\right]}{\sum_{i} \exp \left[\frac{t-t_{i}}{T}\right]}$.

The discontinuous time series of ERS scatterometer measurements, $m_{s}\left(t_{i}\right)$, replaces the continuous parameter $\Theta_{s}(t)$. Equally, $\Theta(t)$ is replaced by a quantity called the soil water index (SWI). Wagner et al. (1999b) have shown that SWI, which (like $m_{s}$ ) may take on values between 0 and 1 , spans the range between $\Theta_{w p}$ and $\Theta_{\max }=\left(\Theta_{f c}+\Theta_{s}\right) / 2$, where $\Theta_{w p}, \Theta_{f c}$ and $\Theta_{s}$ are area-representative values of the wilting point, field capacity and saturation, respectively. Once determined the soil water retention features SWI can be transformed into any other soil water content index. 
ERS scatterometer data since the year 1992 have been processed globally and can be viewed on the website http: //www.ipf.tuwien.ac.at/radar/ers-scat (Scipal et al., 2002). The SWI dataset covers the globe with a $50 \mathrm{~km}$ space resolution and is sampled to a 10 days time frequency. Main improvements with previous versions are related to error modelling and several quality parameters. The snow/ice covered areas and the missing data are masked in the dataset.

SWI has undergone several validation exercises. It has been compared to meteorological information at local and global scales (Wagner, 1998; Scipal, 2002), as well as to in-situ soil moisture measurements (Ceballos et al., 2005). Scipal et al. (2005) processed SWI over the Zambesi river, south-eastern Africa, by means of a logarithmic regression model for obtaining a comparison to hydrometric measurements. Parajka et al. (2006) first compared SWI to soil moisture estimates obtained by hydrological modelling over 320 Austrian catchments, and performed a data assimilation exercise in order to evaluate the potential for improving hydrological predictions in ungauged catchments.

\subsection{The LISFLOOD model}

The LISFLOOD (De Roo et al., 2000, 2001) is a distributed, physically based rainfall-runoff and hydrodynamic model. It simulates processes at the soil-canopy-atmosphere interface, e.g. separation of precipitation into snow and rainfall depending on temperature, interception and evapotranspiration, snow accumulation and melting. The soil compartment of LISFLOOD consists of a two-layer soil model. Infiltration of effective precipitation, soil evaporation and plant water uptake take place from the upper soil layer. The model considers soil freezing, impeding infiltration if a certain threshold is reached. Accordingly, the soil water content of the upper soil layer mirrors well the balance between precipitation supply and climate and vegetation demand. The lower soil layer represents essentially a storage term that produces a slow runoff component and recharges the groundwater compartment. Once infiltrated, water percolates through the bottom soil layer to the groundwater compartment of LISFLOOD. The water transferred to the channel network is routed with either a kinematic or a dynamic wave. While LISFLOOD simulates surface processes using physicallybased algorithms, the subsurface flow modelling routine is conceptual, requiring the calibration of groundwater parameters for individual catchments.

The LISFLOOD model is currently running on a preoperational basis within the European Flood Alert System (EFAS, De Roo and Thielen, 2004) and the European Drought Observatory (EDO, see http://desert.jrc.it). In the current framework, LISFLOOD is set up on a $5 \mathrm{~km}$ grid covering the whole of Europe. The model requires static input information related to topography, soils, land use, and channel geometry. The soil map has been derived from the European Soil Database (ESDB; European Soil Bureau
Network and the European Commission, 2004; see http: //eusoils.jrc.it/ESDB_Archive/ESDBv2/index.htm), and soil hydraulic properties were taken from the HYPRES database (Wösten et al., 1999). Land use-related input maps have been derived from a mosaic of CORINE (European Environment Agency, 2005) and GLC2000 (Bartholomé et al., 2002) land cover databases. A Leaf Area Index (LAI) climatology has been extracted by remotely sensed information. The soil depth obtained by the European Soil Database, ranging between 140 and $3200 \mathrm{~mm}$, is divided among the two soil layers taking into account the rooting depth of the current vegetation cover. Other parameters, such as crop coefficients and crop group number, are linked to land cover through lookup tables.

The meteorological information consists of daily station data provided by the MARS-STAT activity of IPSC-JRC (so called JRC-MARS database; http://mars.jrc.ec.europa. eu/mars/About-us/AGRI4CAST/Data-distribution) that are spatially interpolated. The temporal model flexibility allows for a time-cascading structure: The water balance is simulated with the JRC-MARS data at a daily time step, producing daily soil moisture estimates; its output serves as initial conditions for the flood forecasting mode of EFAS at a finer time step.

The model in the EDO setup has not been calibrated. However, the modelled snow climatology has been verified by means of remotely sensed information; soil moisture and evapotranspiration rates have been checked with respect to literature outcomes and expert knowledge on the climatology of the study area. Moreover, we tested the model ability in capturing drought events as compared to external data sources, obtaining promising results.

\section{Methods}

In order to compare the LISFLOOD first soil layer water content to the ERS scatterometer derived Soil Water Index, we converted the two products into a unique soil moisture representation. We then reprojected and resampled their grids to a common space extent and pixel size and selected the dates available in both the datasets; finally we made pixel by pixel comparisons on the extracted time series. These results were compared to spatial maps of various parameters such as elevation, soil depth, rainfall statistics, and the number of missing or snow covered scatterometer samples.

In order to obtain a unique index of soil water content, SWI has been transformed into available soil moisture $\Theta$ by means of the following equation:

$\Theta=\Theta_{w p}+$ SWI. $\left(\frac{\Theta_{f c}+\Theta_{s}}{2}-\Theta_{w p}\right)$,

where $\Theta_{w p}, \Theta_{f c}$ and $\Theta_{s}$ are area-representative values of the wilting point, field capacity, and saturation. Then both LISFLOOD and SWI-derived available soil moisture have 
been transformed by means of the Van Genuchten pedotransfer function into soil suction $(p F)$ values as follows:

$$
S=\frac{\Theta-\Theta_{r}}{\Theta_{s}-\Theta_{r}}
$$

$h=\frac{1}{\alpha}\left[\left(\frac{1}{S}\right)^{\frac{\lambda+1}{\lambda}}-1\right]^{\frac{1}{\lambda+1}}$

$p F=\log (h)$

where $\Theta, \Theta_{s}$ and $\Theta_{r}$ are the volumetric water content and its saturation and residual values respectively; $S$ is the saturation degree; $h$ is the soil water pressure head; $\alpha$ and $\lambda$ are the Van Genuchten parameters; $p F$ is the so-called soil suction.

Soil suction commonly ranges between 1.0 for very wet conditions up to 5.0 for very dry soils. The $\mathrm{pF}$ value describes the forces necessary for plants to apply in order to extract water from the soil for their use. It incorporates variations in the water holding capacity of different soil types and thus allows for comparison of the soil water status at different locations throughout Europe.

Since soil information is not available for the SWI database, the soil parameters $\Theta_{r}, \Theta_{s}, \Theta_{w p}$ and $\Theta_{f c}$, as well as $\alpha$ and $\lambda$, have been determined from the European Soil Database.

In order to obtain the matching of the observed area and to enable easier comparisons, LISFLOOD $\mathrm{pF}$ maps have been resampled from 5 to $50 \mathrm{~km}$ by averaging the cell values. We chose to perform the resampling directly on $\mathrm{pF}$ values in order not to obtain mismatches between water content and hydraulic properties (e.g. available soil moisture larger than saturation) when averaging samples belonging to different soil texture classes.

With the aim of evaluating the effect of the spatial averaging, we calculated the empirical variogram, which is the function $\gamma(h)$ that measures one half of the average squared difference of data values separated by the lag distance $h$, on a sample of both $\mathrm{pF}$ datasets. We evaluated the amount of variance associated to the resampling operation, which is a measure of the spatial scaling error.

ERS SWI data are available for the years 1992 to 2000 at a 10 days time frequency. In the EDO setup, LISFLOOD data are available from 1990 onwards at a daily frequency. However, since in the years 1990-1995 the number of available meteorological stations is quite poor, we decided to perform the analysis on the available dates in the period 1996-2000.

The two $\mathrm{pF}$ datasets have been compared by means of the root mean square error (RMSE) and the correlation coefficient $(R)$. RMSE and $R$ allow depicting the main differences between the two datasets. In particular, $R$ allows detecting time shifts between the time series that could not be so evident in terms of RMSE if the data have a low overall variability; in the other hand, RMSE allows to evaluate the distance between the curves. For the purposes of this work, it is more acceptable to have a high RMSE, which could be easily cancelled out by means of a quantile-quantile comparison, than a low $R$, hence a significant phase shift among the series. For a major insight into the error structure it is possible to calculate the slope and intercept of the linear regression, as well as to explore by means of cross-correlation whether any significant time shift occurs.

In order to evaluate the relation of the error to any model base information or process representation, we evaluated the amount of variance of RMSE and $R$ that can be explained by the model base maps and to some rainfall statistics and ERS scatterometer processing summary maps.

\section{Results and discussion}

The ERS scatterometer and LISFLOOD modelled datasets have been compared by means of the indices RMSE and $R$ calculated on both the spatial and temporal domains as follows.

When working in the spatial domain, the indices are calculated on all valid data couples for each available date. The resulting RMSE and R time series are presented in Fig. 1. $R$ and RMSE have an average of 0.54 and 0.50 , and a standard deviation of 0.16 and 0.09 , respectively. On the right-hand axis the percent of not valid SWI samples is reported, which have been masked; it has a marked seasonal behaviour because the snow covered samples contribute to the signal as well. Such seasonality effect is partly visible in the indices series.

When working in the temporal domain, the indices are calculated on the $\mathrm{pF}$ time series for each location. The resulting $\mathrm{R}$ and RMSE maps are shown in Figs. 2 and 3. In this case, $R$ and RMSE have an average of 0.48 and 0.45 , and a standard deviation of 0.30 and 0.16 , respectively.

In previous applications of ERS scatterometer, Wagner et al. (1999b), comparing against gravimetric measurements over Ukraine, obtained a (RMSE, $R^{2}$ ) couple of $0.05 \mathrm{~m}^{3} \mathrm{~m}^{-3}$ and 0.25; Wagner et al. (2003), comparing against precipitation at the global scale, 0.03 to $0.07 \mathrm{~m}^{3} \mathrm{~m}^{-3}$ and 0.25 ; Ceballos et al. (2005), comparing against TDR measurements over NW Spain, $0.02 \mathrm{~m}^{3} \mathrm{~m}^{-3}$ and 0.75; Scipal (2002), comparing against gravimetric and neutron probe measurements over China, Russia, Ukraine, India, and Illinois, 0.05 to 0.08 $\mathrm{m}^{3} \mathrm{~m}^{-3}$ and 0.27 to 0.6. In a comparison between ERS scatterometer and optical and thermal infrared applications over European forests, Verstraeten et al. (2006) obtained a $R^{2}$ of 0.441 and a RMSE of $0.082 \mathrm{~m}^{3} \mathrm{~m}^{-3}$. With respect to soil moisture estimates obtained by means of hydrological modelling, Parajka et al. (2006) obtained an average correlation coefficient over Austria of 0.27. 


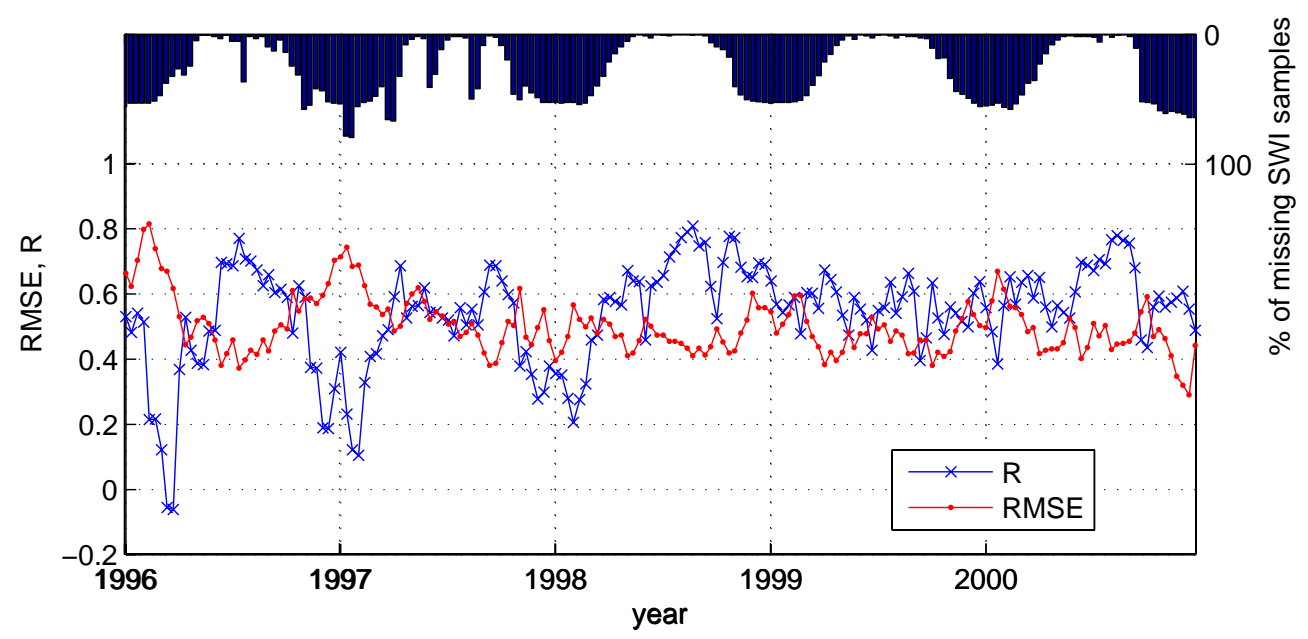

Fig. 1. pF Lisflood-pF ERS R and RMSE time series. In the right-hand axis the percent of not valid SWI samples is reported.

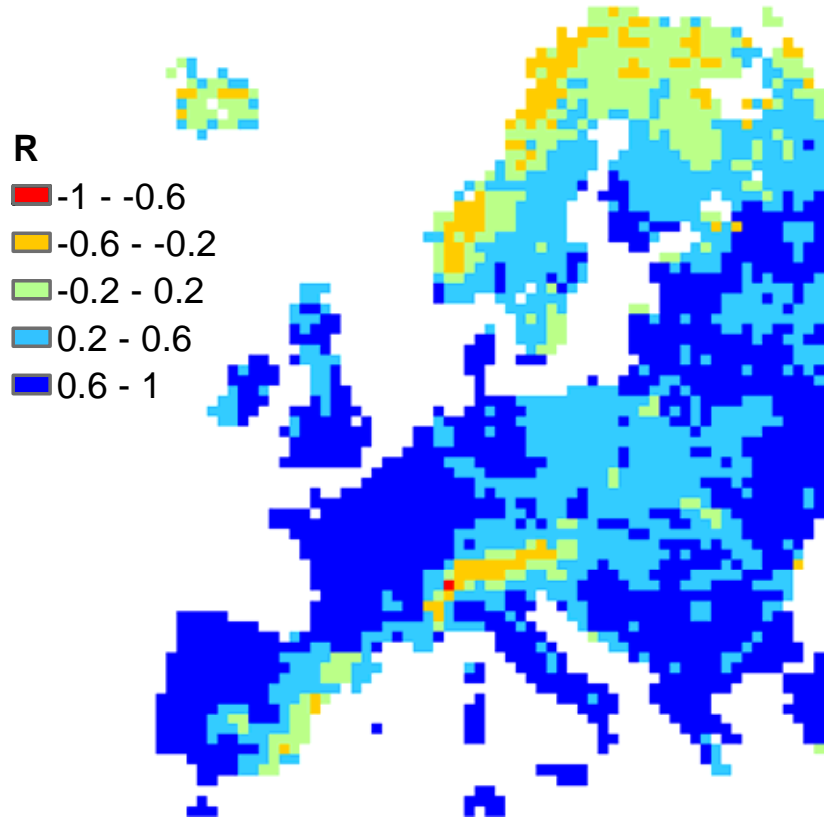

Fig. 2. pF Lisflood-pF ERS comparison. Correlation coefficient map.

In order to make the RMSE obtained on $\mathrm{pF}$ series comparable to literature results we estimated that, given the soil texture features, a $0.05 \mathrm{~m}^{3} \mathrm{~m}^{3}$ error ranges between 0.38 and $1.03 \mathrm{pF}$ units at wilting level and between 0.23 and $0.60 \mathrm{pF}$ units at field capacity.

We combined the RMSE and R maps into a class map (Fig. 4) obtained by binning RMSE and $R$ as shown in Table 1 . In the class map it is easier to delineate the spatial patterns of the errors.

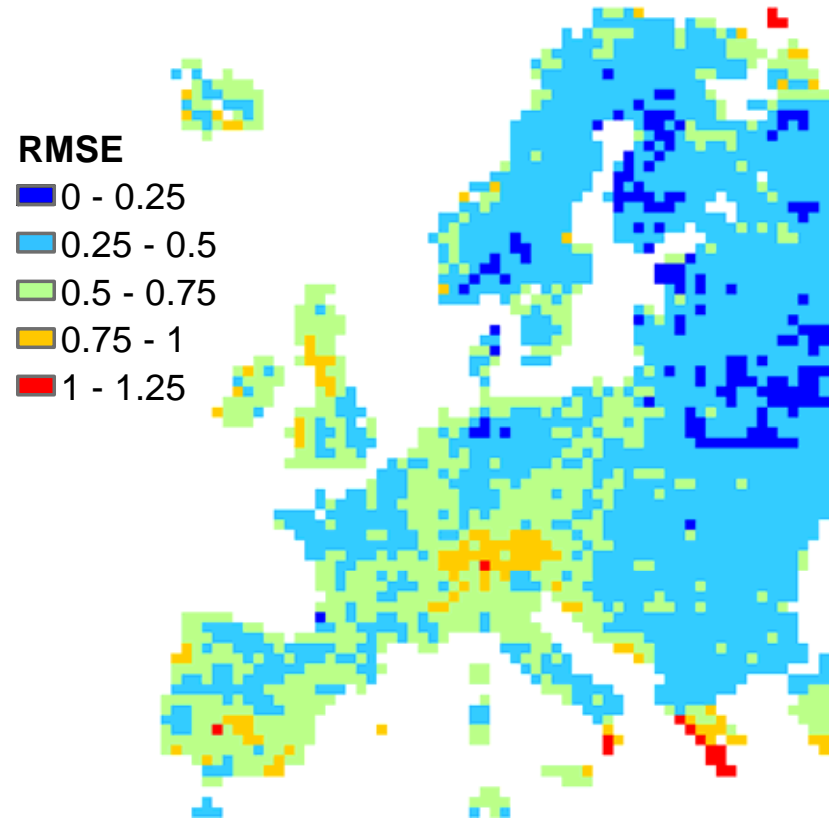

Fig. 3. pF Lisflood-pF ERS comparison. RMSE map.

For evaluating the influence of the scale mismatch between the two datasets on the results, we calculated the empirical semi-variogram for a $10^{6} \mathrm{~km}^{2}$ square section of the soil moisture maps located in central Europe. The choice of such extent allows us to skip the problems arising when working on a fragmented domain. In order to detect any seasonality effect we processed all the maps available for the entire period; the results for 1998 are presented. 


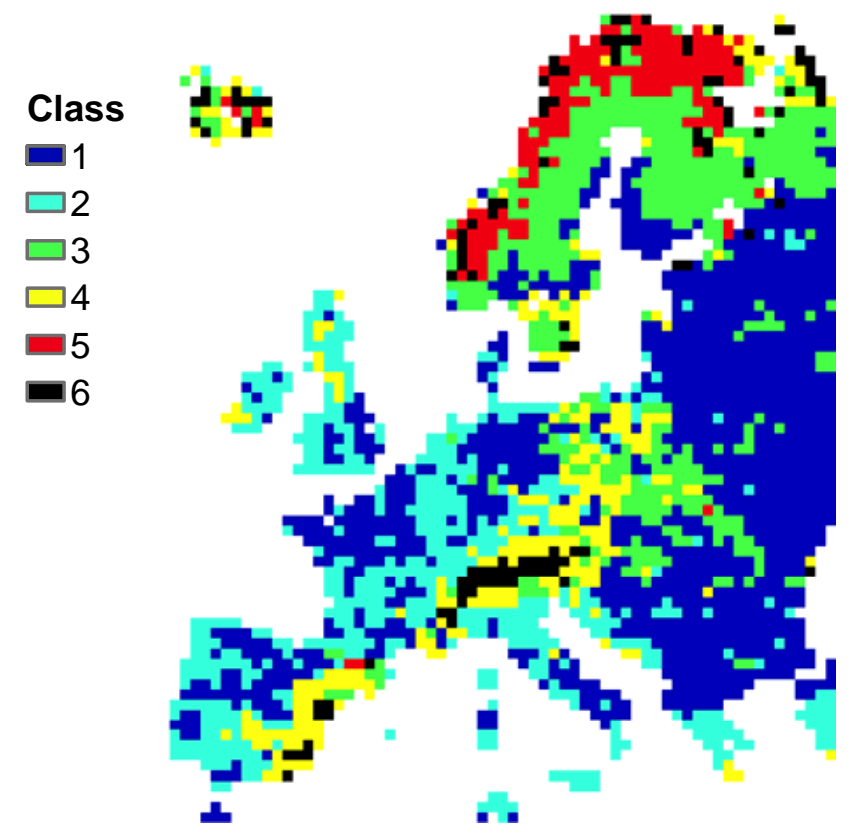

Fig. 4. Map of the six error classes defined in Table 1.

Table 1. Definition of the classes shown in Fig. 4. The percent of samples in each class is reported.

\begin{tabular}{lllrlr}
\hline Class & \multicolumn{2}{l}{ RMSE bins } & \multicolumn{2}{c}{ R bins } & \% samples \\
\hline 1 & 0 & 0.5 & 0.5 & 1 & $41.4 \%$ \\
2 & 0.5 & 1.2 & 0.5 & 1 & $20.0 \%$ \\
3 & 0 & 0.5 & 0 & 0.5 & $18.6 \%$ \\
4 & 0.5 & 1.2 & 0 & 0.5 & $9.9 \%$ \\
5 & 0 & 0.5 & -1 & 0 & $5.8 \%$ \\
6 & 0.5 & 1.2 & -1 & 0 & $4.4 \%$ \\
\hline
\end{tabular}

The results of the variogram analysis allow evaluating which is the amount of sub-pixel variability expected if a ERS scatterometer pixel is compared to the underlying LISFLOOD pixels; moreover, they give an idea on what could be the error associated to a spatial misplacement among the two datasets.

The boxplots in Figs. 5 and 6 represent a summary of the semi-variograms for all the available dates in 1998. At the $250 \mathrm{~km}$ lag both the datasets present a median semi-variance of 0.06. The ERS scatterometer median semi-variogram shows a quite linear behaviour, giving the impression that it has not reached yet the sill; the LISFLOOD one has a rapid increase, then approaching a rather asymptotic behaviour, being in the explored range of lags major than the ERS scatterometer one. Such behaviour, with the short lags being dominated by the larger variability of the higher resolution

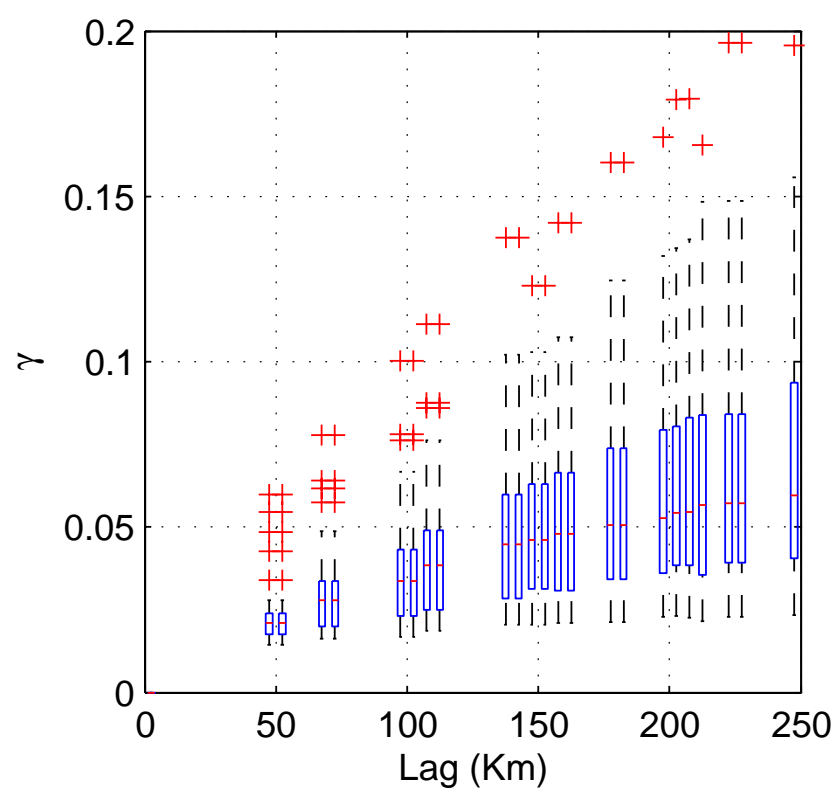

Fig. 5. Summary of the semi-variograms of the ERS scatterometer derived $\mathrm{pF}$ maps for all the available dates in 1998.

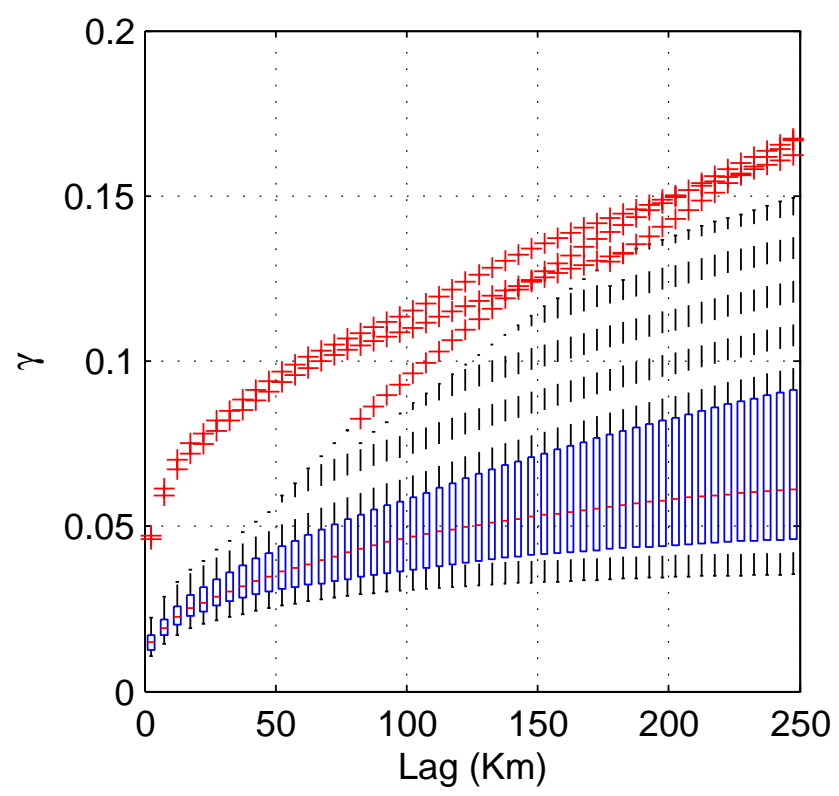

Fig. 6. Summary of the semi-variograms of the LISFLOOD derived pF maps for all the ERS scatterometer pF available dates in 1998.

data, is deemed to be acceptable: the finer scales of the basic information (e.g. soil depth, land use) for the model have an effect. At larger scales, the meteorological forcings dominate the response of both the models and a better agreement is observed. 


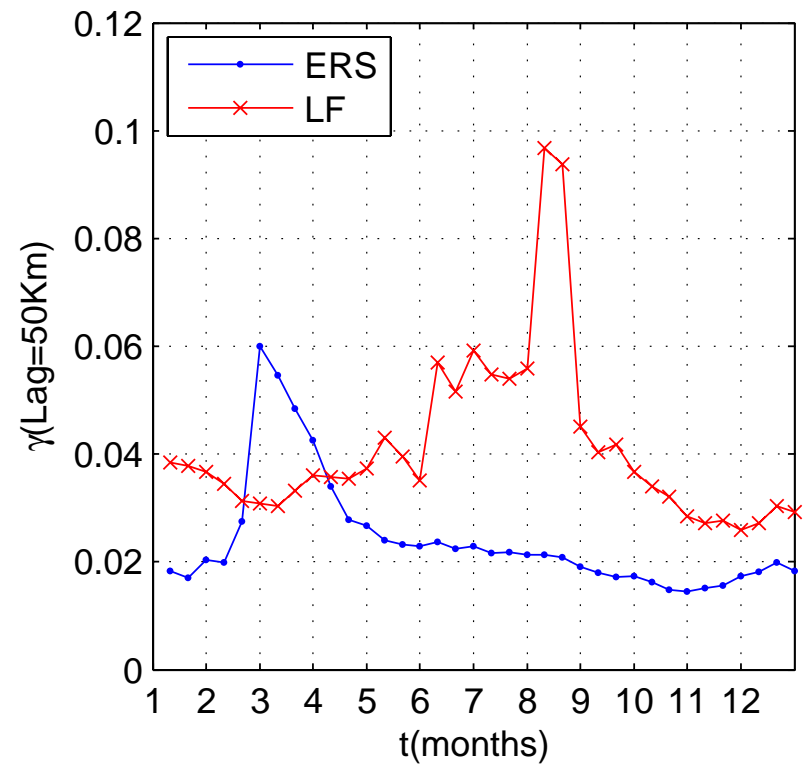

Fig. 7. Time series of the $50 \mathrm{~km}$ lag semi-variance of the ERS scatterometer (blue) and LISFLOOD (red) derived pF maps for 1998.

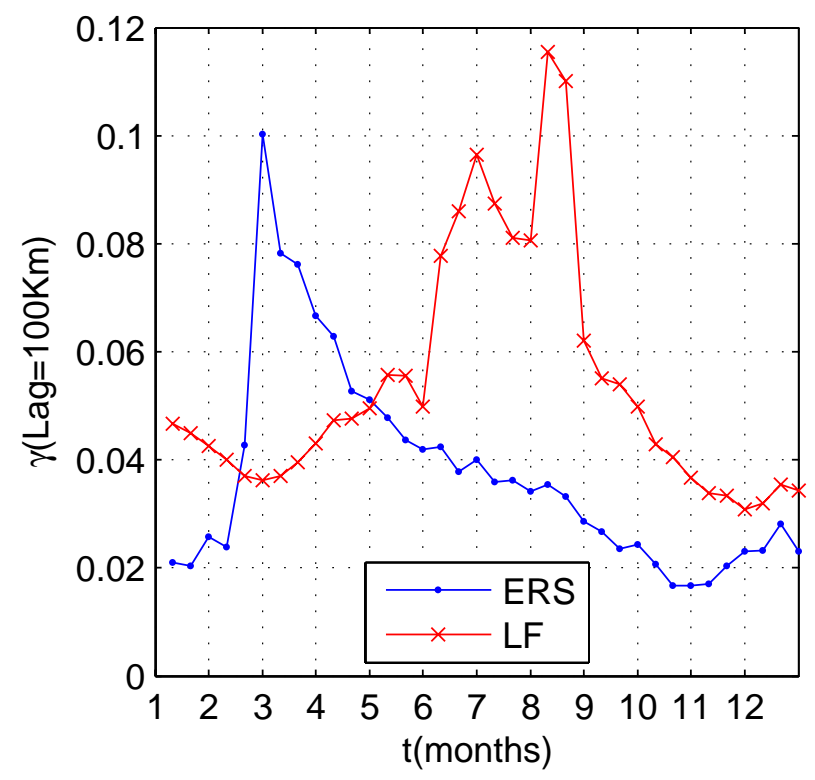

Fig. 8. Time series of the $100 \mathrm{~km}$ lag semi-variance of the ERS scatterometer (blue) and LISFLOOD (red) derived $\mathrm{pF}$ maps for 1998.

In order to mimic the model behaviour at the short scales by means of ERS Scatterometer it is possible to combine the coarse resolution satellite data and other static information having a higher resolution within a model, e.g. calculating SWI on a mapped soil depth.
Table 2. Ratio of the RMSE and R variances that can be explained by the selected predictors.

\begin{tabular}{lrr}
\hline Predictor & \multicolumn{2}{c}{ Explained variance } \\
\cline { 2 - 3 } & RMSE & $R$ \\
\hline Elevation (Fig. 9) & $8 \%$ & $8 \%$ \\
1st layer soil depth (Fig. 10) & $18 \%$ & $0 \%$ \\
Average annual rainfall (Fig. 11) & $11 \%$ & $0 \%$ \\
Annual rainfall coefficient & & \\
of variation (Fig. 12) & $4 \%$ & $1 \%$ \\
$\%$ of missing samples (Fig. 13) & $15 \%$ & $10 \%$ \\
\% of snow/ice & & \\
covered samples (Fig. 14) & $20 \%$ & $26 \%$ \\
\hline
\end{tabular}

Figures 7 and 8 represent the time series of the median semi-variance at the $50 \mathrm{~km}$ and $100 \mathrm{~km}$ lags for both the datasets. It is evident a rather different seasonal behaviour: the ERS scatterometer derived maps have larger spatial variability in winter-spring, the LISFLOOD ones in summer. The satellite early spring behaviour is deemed to be related to snowmelt processes and to the shortcomings of the start-up of the SWI calculation routine (Eq. 3). In other seasons the variability is lower, as expected by a lower resolution dataset. On the contrary, the LISFLOOD response has a more evident spatial variability in summer, when the drier conditions let the contrasting land surface properties become more evident.

The root of the median variance for a $25 \mathrm{~km}$ lag is $0.17 \mathrm{pF}$ units, which corresponds on average to $0.014 \mathrm{~m}^{3} \mathrm{~m}^{3}$. As a reference, Ceballos et al. (2005), working on a $2500 \mathrm{~km}^{2}$ area with a network of 20 TDR stations, reported a time averaged standard deviation of plant available water of $0.034 \mathrm{~m}^{3} \mathrm{~m}^{3}$. Table 2 reports the percentages of RMSE and $\mathrm{R}$ variances that can be explained both by static information (elevation and soil depth) and statistics of the meteorological inputs (average annual rainfall and annual rainfall coefficient of variation) for the LISFLOOD model, and by summary statistics of the ERS SWI data (percent of missing and snow covered dates). The boxplots presented in Figs. 9 to 14 allow having an insight into the relations between the predictands and the predictors.

Figure 9 shows that the goodness of fit has an evident decreasing trend when terrain elevation increases. Elevation has a key role in soil moisture space-time variability since it strongly controls the distribution of several meteorological variables, such as air temperature and potential evapotranspiration, or precipitation amount and phase (rain/snow).

Figure 10 represents the distribution of RMSE and $R$ within soil depth bins. It shows that shallow soils have large RMSE and low $R$. Since the SWI calculation is based on a constant $1 \mathrm{~m}$ soil depth over the whole area, a better correspondence for deep soils is obtained. The water content of a shallow soil has a pronounced extreme behaviour, with values jumping easily from saturation to wilting level. On 

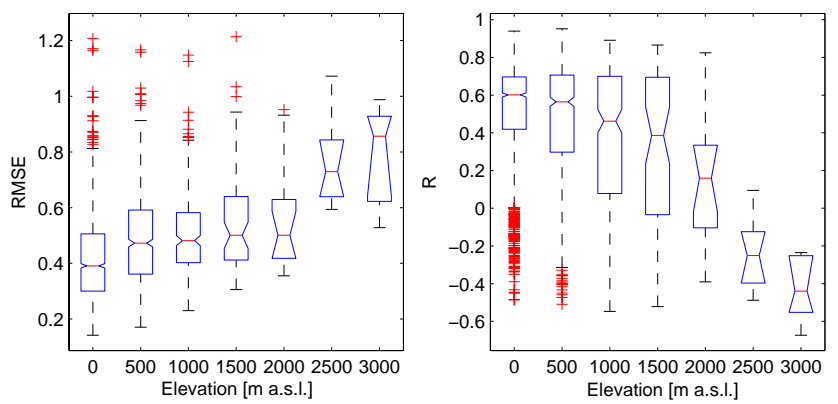

Fig. 9. RMSE and Correlation coefficient distributions within elevation bins.
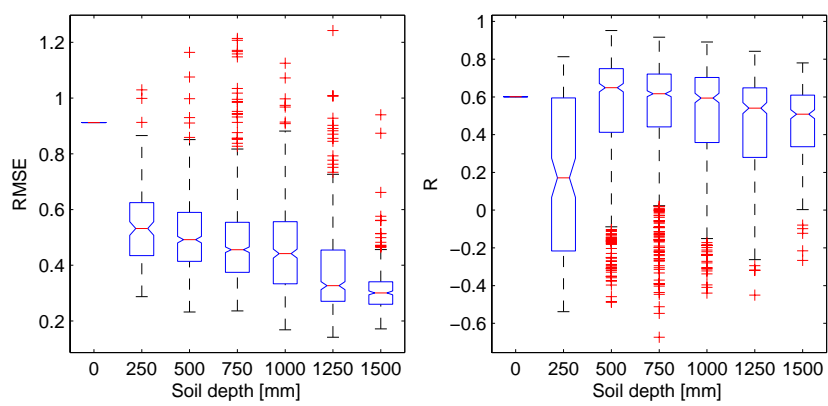

Fig. 10. RMSE and Correlation coefficient distributions within soil depth bins.
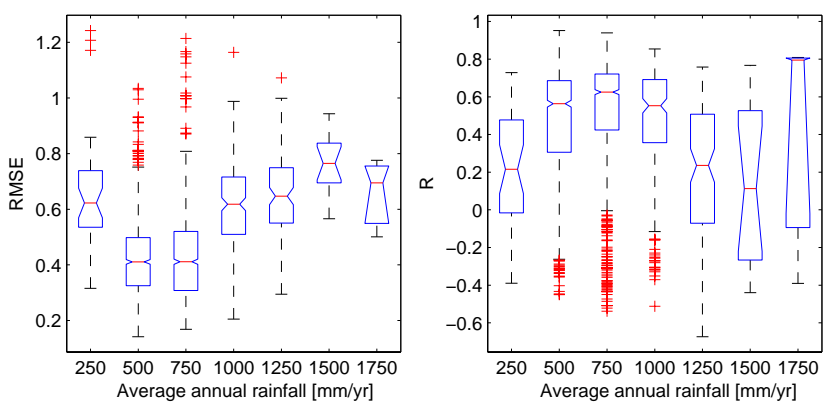

Fig. 11. RMSE and Correlation coefficient distributions within average annual rainfall bins.

the contrary, deep soils have more homogeneous water content over a large range of depths. In order to overcome the inconsistent reference soil depth of SWI values and LISFLOOD derived soil moisture, either the SWI calculation could be repeated on a spatially differentiated soil depth, or the LISFLOOD model run could be performed on a fixed $1 \mathrm{~m}$ one. We would recommend the first choice; however major problems in the SWI algorithm parameterization could occur. Soil texture has not been investigated since its influence has been cancelled out by the use of $p F$, and the preparation of both $\mathrm{pF}$ datasets by means of the same soil texture map.
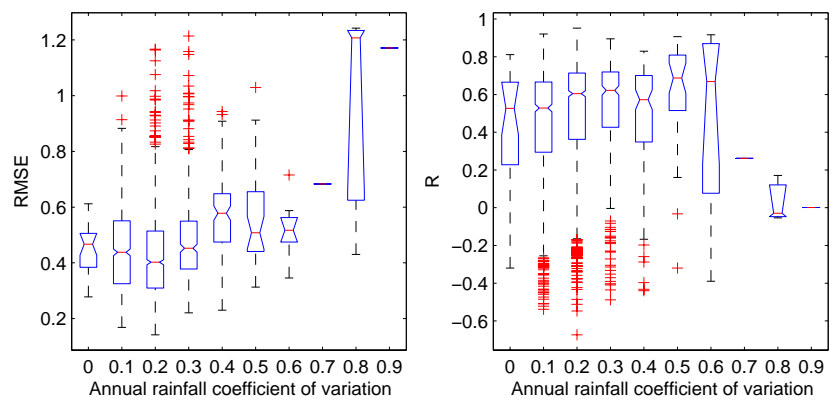

Fig. 12. RMSE and Correlation coefficient distributions within annual rainfall coefficient of variation bins.
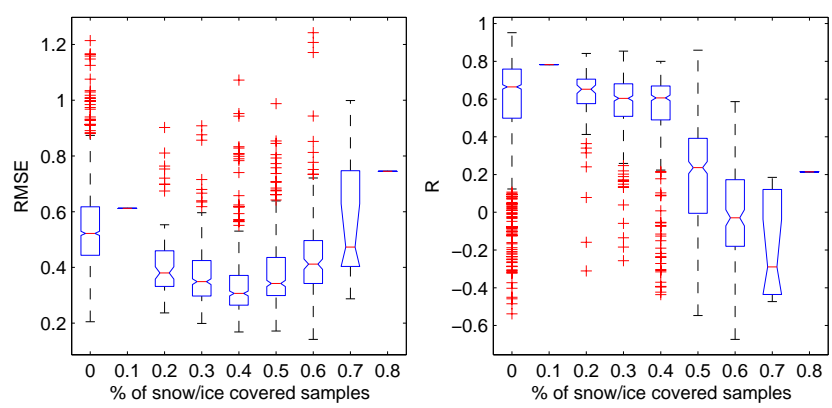

Fig. 13. RMSE and Correlation coefficient distributions within percent of missing SWI samples bins.
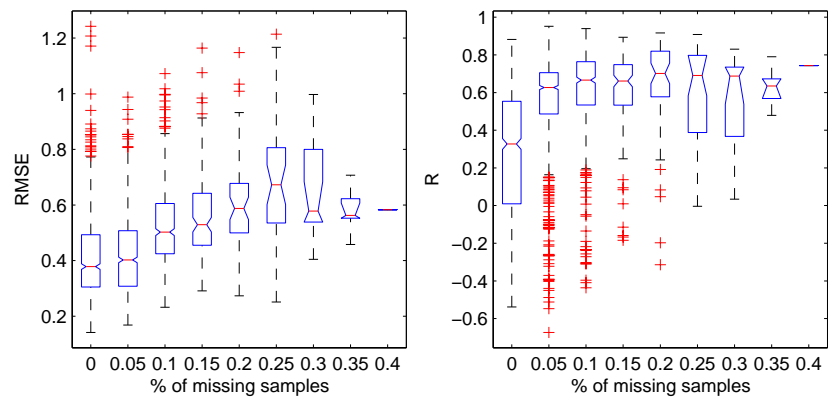

Fig. 14. RMSE and Correlation coefficient distributions within percent of snow covered SWI samples bins.

The statistics of the annual rainfall (its average and coefficient of variation) have been considered for both evaluating the reliability of the meteorological input data and of the interpolation procedures, and assessing the relations between the $\mathrm{pF}$ datasets in different climatic divisions. $\mathrm{Ob}$ serving the distribution of RMSE and $R$ within average annual rainfall bins (Fig. 11) it is difficult to figure out a homogeneous behaviour. This can be partly explained by the fact that a sample with a certain error in rainfall representation falls into a bin where valid samples exist. However, it is possible to observe that both RMSE and $R$ are worse in 

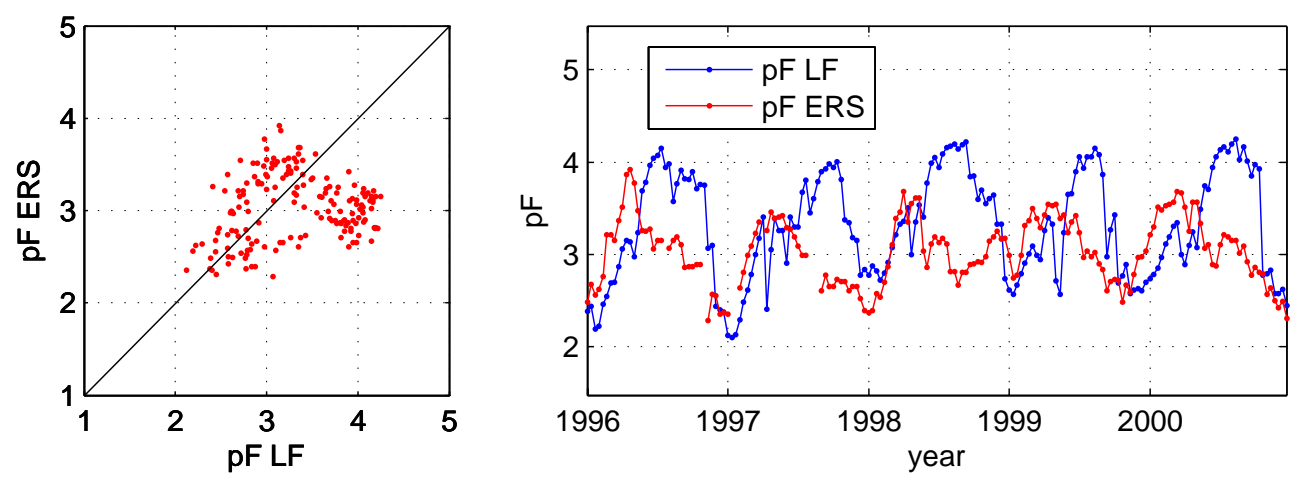

Fig. 15. ERS scatterometer and LISFLOOD derived $\mathrm{pF}$ time series for a sample with extended irrigation practice.

extreme (both drier and wetter) climatic conditions. In such conditions the change detection approach used in the processing chain of the ERS scatterometer data is weaker, since the dry and wet thresholds are not reached in wet and dry climate divisions, respectively. The model as well could suffer under such circumstances, e.g. becoming less sensitive to inter-annual variations (e.g. a particularly wet year in a wet region and viceversa). However, we did not experience such kind of behaviour.

The coefficient of variation (CV) of a hydrological variable is often considered in regional analysis studies since it allows delineating homogeneous regions. On the other hand, high CV can be related to data having poor accuracy in a certain area. In Fig. 12, the bins with the highest rainfall CV have lower $R$ and higher RMSE.

The percent of missing and snow/ice covered ERS samples affect the SWI calculation in certain regions, as confirmed by the variances of RMSE and $R$ explained by such variables (see Table 2). The most evident effect of the number of missing samples (see Fig. 13) is an increase in RMSE, while $R$ is not significantly affected. The missing ERS scatterometer acquisitions can be deemed to be randomly distributed within a time series in a certain location; the algorithm for the calculation of SWI is able to face to few consecutive missing dates with a slight deviation from the observed soil moisture development. This causes almost no effects in terms of $R$ (the seasonal behaviour is still respected), while RMSE increases (accumulation of deviations at the short time scales). On the contrary, the increase of snow/ice covered samples affects more significantly $R$ (see Fig. 14). In cold regions the missing data are clustered into one season; at the end of the cold period, the algorithm has to start from an initial condition that can be deemed to be a guess, leading to poor representation of seasonality, hence low $R$. In the other hand, the seasonal soil moisture variability is quite low, so the effects on RMSE are not so evident.
Despite being obtained in a completely independent way, the ERS SWI derived and the LISFLOOD modelled soil suction have a good agreement over large regions, with almost $90 \%$ of the area having a positive $R$ and $66 \%$ having RMSE $<0.5$. The two datasets show large differences in the Alpine region, in eastern Spain, in northern Scandinavia and on the Carpathian mountains.

The main differences between the two $\mathrm{pF}$ timeseries can be observed in the mountainous areas, as confirmed by the variances explained by the elevation and the percent of snow/ice affected ERS samples. Parajka et al. (2006) obtained similar results over Austria. In mountainous regions both datasets have to face a strongly heterogeneous landscape with large gradients in hydrological processes. The poor spatial resolution of ERS data cannot account for such heterogeneity. In addition, since the ERS soil moisture data availability is strongly reduced in areas where snow a ice frequently hide the surface, it is expected that also the SWI calculation is affected, as previously explained.

With regard to LISFLOOD soil moisture modelling, the morphologic complexity as well as the uneven distribution of meteorological stations and their low spatial representativeness cause major uncertainties in meteorological data retrieval, which affect the quality of the modelled snow accumulation and melting.

In summary, the representation of soil moisture processes in the mountainous regions remains unsolved on the spatial scales considered: neither ERS $\mathrm{pF}$ data can be considered being reliable, nor do the related processes as modelled by LISFLOOD produce fully satisfying results.

In addition to the mentioned problems related to snow, in Scandinavia the significant presence of water bodies affects the soil moisture retrieval for both methods. Apart from the difficulties related to the correct superimposition of the surface parameters (e.g. land use and soil maps) in such a fragmented landscape, it is not possible to calibrate the hydro- 
logic model against observed discharge because it is strongly influenced by the retention effect of the lakes. Also the microwave signal is strongly affected by the large surface covered by free water (Wagner et al., 1999b).

With regards to eastern Spain, by means of visual inspection of the time series we discovered that in certain locations the effect of irrigation practices is quite evident: in winter the time series agree quite well, while during summer major differences occur, with ERS $p F$ being well below LISFLOOD $p F$ (see, e.g. Fig. 15). The satellite data are able to detect irrigation, while, on the contrary, irrigation is not simulated by the LISFLOOD model. In order to gain evidence of the actually irrigated areas in eastern Spain, in Fig. 16 we superimposed the classified error map reported in Fig. 4 to the Global Map of Irrigation Areas (Siebert et al., 2006, 2007). The hypothesis of a strong influence due to irrigation was confirmed. It is worth to mention that it is possible to detect the influence of irrigation over Spain because of its strong control over soil moisture seasonality in that area. In areas where irrigation supply is used as a minor addition to rain-fed agriculture, a negligible signature on the soil moisture cycle is expected; accordingly, in other irrigated areas no influence of irrigation on ERS-derived soil moisture could be detected.

However, irrigation practice explains the mismatch of the time series for a limited number of locations. Other areas are affected by the high amount of missing SWI samples. We feel that also some problems related to the change detection occurred, with certain areas having low $p F$ in summer and high $p F$ in winter. In dry areas it is difficult to detect the dry and wet references and it is necessary to correct them manually (Wagner et al., 2003).

Provided the limitations mentioned above, we believe that the ERS scatterometer can represent a valuable source of information for hydrological applications. Its usage "as is" at the current spatial resolution could be valuable for studies in ungauged/poorly known areas. Moreover it is worth to explore the possibility of obtaining much detailed spatial information by means of a suitable tuning of the SWI parameters based on ancillary information at a higher resolution, e.g. mapped soil depths and potential evapotranspiration rates. Finally, the information on the top-soil water content could be assimilated in a model comprising in its structure a layer of comparable depth. This kind of approach could be meaningful for large scale applications, where the spatial scale of the scatterometer well matches the one of the driving meteorological phenomena, which are often poorly mapped in remote regions.

The result of the comparison, despite it can not be properly considered a validation exercise, allows us to be more confident in the LISFLOOD modelled estimates. In addition, it has been possible to discriminate some potential sources of error, such as the treatment of snow and ice processes, and to have an insight on scale effects in view of further model development related, e.g. to sub-pixel model parameterization.

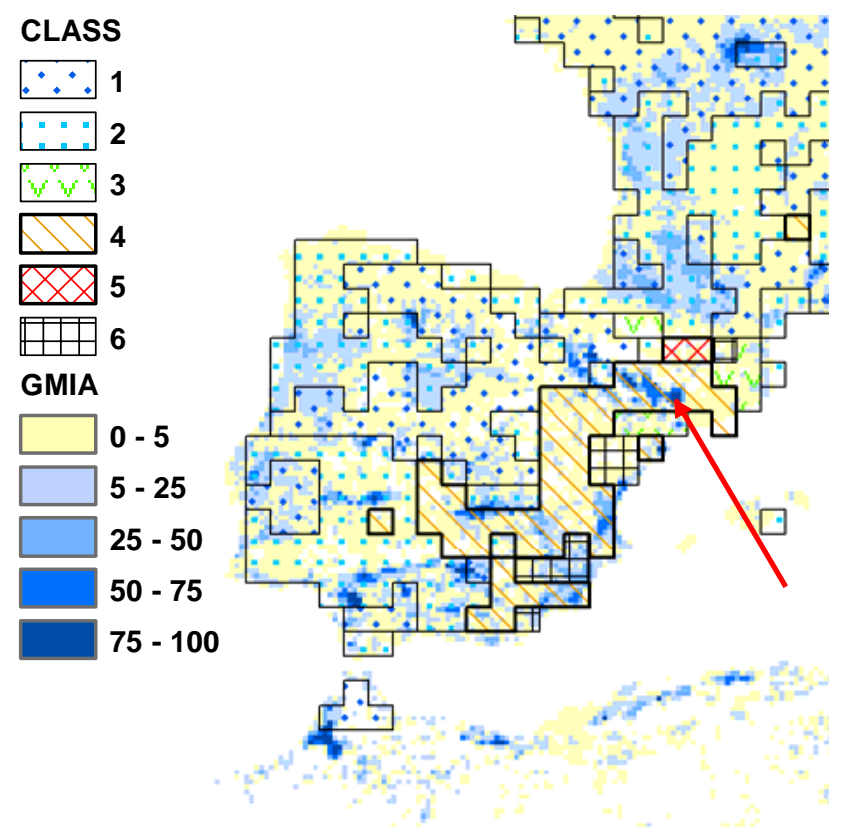

Fig. 16. Error class map (CLASS) superimposed to the Global Map of Irrigation Areas (GMIA; Siebert et al., 2006, 2007) over the Iberian Peninsula. GMIA reports the percent of the surface having infrastructures for irrigation; in white pixels no information is available. The arrow highlights the sample whose time series is plotted in Fig. 15.

\section{Conclusions}

The comparison between the LISFLOOD modelled and the ERS/SCAT derived soil moisture products has revealed that the two datasets match well over large regions, particularly in lowlands and in areas far from extreme climatic conditions. The correlation coefficient is positive over $90 \%$ of the area; the root mean square error is minor than $0.5 \mathrm{pF}$ units (approximately $0.045 \mathrm{~m}^{3} \mathrm{~m}^{3}$ ) over the $66 \%$ of the area. The major inconsistencies are located in the Alps and in the Scandinavia regions, where both models suffer because of the uncertainty of the available information, namely the limited availability of satellite data and the poor behaviour in heterogeneous landscapes at the given spatial resolution of ERS SWI data on the one hand, and the uncertainties in meteorological data retrieval and interpolation as well as in snow-ice modelling of the LISFLOOD model on the other hand.

For further analyses ground measurements and other satellite products will be considered in forthcoming works.

Acknowledgements. The authors would like to thank the Microwaves Remote Sensing Group of the Vienna University of Technology for providing the ERS scatterometer data and for the fruitful discussions.

Edited by: N. Verhoest 


\section{References}

Alfieri, L., Claps, P., D’Odorico, P., Laio, F., and Over T. M.: An analysis of the soil moisture feedback on convective and stratiform precipitation, J. Hydrometeorol., 9(2), 280-291, 2008.

Avissar, R. and Pielke, R. A.: A parameterization of heterogeneous land surfaces for atmospheric numerical models and its impact on regional meteorology, Mon. Weather Rev., 117(10), 2113-2136, 1989.

Bartholomé, E., Belward, A. S., Achard, F., Bartalev, S., Carmona-Moreno, C., Eva, H., Fritz, S., Gregoire, J.-M., Mayaux, P., and Stibig, H.-J.: GLC 2000: Global Land Cover mapping for the year 2000, EUR 20524 EN, available at: http://www-tem.jrc.it/glc2000/Publications/GLC2000\% 20EUR20524_report_v2.pdf, 2002.

Beljaars, A. C. M. and Viterbo, P.: Soil moisture-precipitation interaction: Experience with two land surface schemes, in: the ECMWF model, Global energy and water cycles, edited by: Browning, K. and Gurney, R., Cambridge University Press, Cambridge, 223-233, 1999.

Carlson, T. N., Gillies, R. R., and Schmugge, T. J.: An interpretation of methodologies for indirect measurement of soil water content, Agric. Forest Meteorol., 77, 191-205, 1995.

Castelli, F., Entekhabi, D., and Caporali, E.: Estimation of surface heat flux and an index of soil moisture using adjoint-state surface energy balance, Water Resour. Res., 35(10), 3115-3125, 1999.

Castelli, F., Rodriguez-lturbe, I., and Entekhabi, D.: An analytical framework for the modeling of the spatial interaction between the soil moisture and atmosphere, J. Hydrol., 184(1), 19-34, 1996.

Ceballos, A., Scipal, K., Wagner, W., and Martínez-Fernández, J.: Validation of ERS scatterometer-derived soil moisture data in the central part of the Duero Basin, Spain, Hydrol. Process., 19, 1549-1566, 2005.

De Lannoy, G. J. M., Houser, P. R., Verhoest, N. E. C., Pauwels, V. R. N., and Gish, T. J.: Upscaling of point soil moisture measurements to field averages at the $\mathrm{OPE}^{3}$ test site, J. Hydrol., 343(1-2), 1-11, 2007.

De Roo, A. and Thielen, J.: The European Flood Alert System, In: J. Thielen and A. De Roo (eds.), 2nd EFAS Workshop, Joint Research Centre, European Commission, Ispra, 2004.

De Roo, A. P. J., Odijk, M., Schmuck, G., Koster, E., and Lucieer, A.: Assessing the effects of land use changes on floods in the Meuse and Oder catchment, Phys. Chem. Earth Pt. B, 26(7-8), 593-599, 2001.

De Roo, A. P. J., Wesseling, C. G., and Van Deurzen, W. P. A.: Physically based river basin modelling within a GIS: the LISFLOOD model, Hydrol. Process., 14, 1981-1992, 2000.

Ek, M. B., Mitchell, K. E., Lin, Y., Rogers, E., Grunmann, P., Koren, V., Gayno, G., and Tarpley, J. D.: Implementation of Noah land surface model advances in the National Centers for Environmental Prediction operational mesoscale Eta model, J. Geophys. Res., 108(D22), 8851, 2003.

Engman, E. T. and Chauhan, V.: Status of microwave soil moisture measurements with remote sensing, Remote Sens. Environ., 51(1), 189-198, 1995.

European Environment Agency: CORINE land cover 2000, available at: http://dataservice.eea.europa.eu/dataservice/available2. asp?type $=$ findkeyword $\&$ theme $=$ clc2000 (last acces: December 2008), 2005.

European Soil Bureau Network and the European Commission: Eu- ropean Soil Database (v 2.0), EUR 19945 EN, 2004.

Ferranti, L. and Viterbo, P: The European Summer of 2003: sensitivity to soil water initial conditions, J. Climate, 19(15), 36593680, 2006.

Grayson, R. B. and Western, A. W.: Towards areal estimation of soil water content from point measurements: time and space stability of mean response, J. Hydrol., 207(1-2), 68-82, 1998.

Hirschi, M., Viterbo, P., and Seneviratne, S. I.: Basin-scale waterbalance estimates of terrestrial water storage variations from ECMWF operational forecast analysis, Geophys. Res. Lett., 33, L21401, doi:10.1029/2006GL027659, 2006.

Kite, G. and Droogers, P.: Comparing evapotranspiration estimates from satellites, hydrological models and field data, J. Hydrol., 229, 3-18, 2000.

Luo, L. and Wood, E. F.: Monitoring and predicting the 2007 U.S. drought, Geophys. Res. Lett., 34, L22702, doi:10.1029/2007GL031673, 2007.

Martínez-Fernández, J., and Ceballos, A.: Mean soil moisture estimation using temporal stability analysis, J. Hydrol., 312(1-4), 28-38, 2005.

McVicar, T. R. and Jupp, D. L. B.: The current and potential operational uses of remote sensing to aid decisions on drought exceptional circumstances in Australia: a review, Agric. Syst., 57(3), 399-468, 1998.

Niemeyer, S.: Modelling the surface energy balance on the regional scale with remote sensing and meteorological network data, European Commission, EUR 19523, 260 pp., 2000.

Nishida, K., Nemani, R. R., Glassy, J. M., and Running, S. W.: Development of an evapotranspiration index from Aqua/MODIS for monitoring surface moisture status, IEEE T. Geosci. Remote, 41(2), 493-501, 2003.

Parajka, J., Naeimi, V., Bl“schl, G., Wagner, W., Merz, R., and Scipal, K.: Assimilating scatterometer soil moisture data into conceptual hydrologic models at the regional scale, Hydrol. Earth Syst. Sci., 10, 353-368, 2006, http://www.hydrol-earth-syst-sci.net/10/353/2006/.

Price, J. C.: The potential of remotely sensed thermal infrared data to infer surface soil moisture and evaporation, Water Resour. Res., 16(4), 787-795, 1980.

Refsgaard, J. C.: Towards a formal approach to calibration and validation of models using spatial data, in: Spatial patterns in catchment hydrology: observations and modelling, edited by: R. Grayson and G. Blöschl, Cambridge University Press, 329-354, 2000.

Rodriguez-Iturbe, I., Vogel, G. K., Rigon, R., Entekhabi, D., Castelli, F., and Rinaldo, A.: On the spatial organization of soil moisture fields, Geophys. Res. Lett., 22(20), 2757-2760, 1995.

Scanlon, T. M., Caylor, K. K., Manfreda, S., Levin, S. A., and Rodriguez-Iturbe, I.: Dynamic response of grass cover to rainfall variability: implications for the function and persistence of savanna ecosystems, Adv. Water Resour., 28, 291-302, 2005.

Schmugge, T. J.: Applications of Passive Microwave Observations of Surface Soil Moisture, J. Hydrol., 212-213, 188-200, 1998.

Scipal, K., Naeimi, V., and Hasenauer, S.: Definition of Quality Flags, ASCAT Soil Moisture Report Series, No. 7, Institute of Photogrammetry and Remote Sensing, Vienna University of Technology, available at: http://www.ipf.tuwien.ac.at/ radar/ascat/report_series/07_Quality\%20Flags_v2.0.pdf, (last access: December 2008), 2005. 
Scipal, K., Scheffler, C., and Wagner, W.: Soil moisture-runoff relation at the catchment scale as observed with coarse resolution microwave remote sensing, Hydrol. Earth Syst. Sci., 9, 173-183, 2005, http://www.hydrol-earth-syst-sci.net/9/173/2005/.

Scipal, K., Wagner, W., Trommler, M., and Naumann, K.: The Global Soil Moisture Archive 1992-2000 from ERS scatterometer data: first results, in: Proceedings of IGARRS'2002, Toronto, Canada, 24-28 June 2002, 2002.

Scipal, K.: Global soil moisture retrieval from ERS Scatterometer data, Ph.D. thesis, Vienna University of Technology, Austria, available at http://www.ipf.tuwien.ac.at/radar/ascat/publ/ 0014.pdf (last access: December 2008), 2002.

Seneviratne, S. I., Viterbo, P., Lüthi, D., and Schär, C.: Inferring changes in terrestrial water storage using ERA-40 reanalysis data: the Mississippi river basin, J. Climate, 17, 2039-2057, 2004.

Siebert, S., Döll, P., Feick, S., Frenken, K., and Hoogeveen, J.: Global map of irrigation areas version 4.0.1., University of Frankfurt (Main) and FAO, Rome, Italy, 2007.

Siebert, S., Hoogeveen, J., and Frenken, K.: Irrigation in Africa, Europe and Latin America. Update of the Digital Global Map of Irrigation Areas to Version 4, Frankfurt Hydrology Paper 05, University of Frankfurt (Main), Germany and FAO, Rome, Italy, available at: http://www.geo.uni-frankfurt.de/fb/fb11/ipg/ ag/dl/f_publikationen/2006/FHP_05_Siebert_et_al_2006.pdf (last access: December 2008), 2006.

Starks, P. J., Heathman, G. C., Jackson, T. J., and Cosh, M. H.: Temporal stability of soil moisture profile, J. Hydrol., 324(1-4), 400-411, 2006.

Thielen, J., Bartholmes, J., Ramos, M.-H., and de Roo, A.:

The European Flood Alert System - Part 1: Concept and development, Hydrol. Earth Syst. Sci. Discuss., 5, 257-287, 2008, http://www.hydrol-earth-syst-sci-discuss.net/5/257/2008/.

Vachaud, G., DeSilans, A. P., Balabanis, P., and Vauclin, M.: Temporal stability of spatially measured soil water probability density function, Soil Sci. Soc. Am. J., 49(4), 822-828, 1985.
Van der Knijff, J. and de Roo, A.: LISFLOOD: Distributed Water Balance and Flood Simulation Model, JRC Scientific and Technical Reports, EUR 22166 EN/2, available at: http://natural-hazards.jrc.ec.europa.eu/downloads/pdf/ec_jrc lisfloodUserManual_JvdK-AdR.pdf, 2008.

Verhoest, N. E. C., Lievens, H., Wagner, W., Álvarez-Mozos, J., Moran, M. S., and Mattia, F.: On the soil roughness parameterization problem in soil moisture retrieval of bare surfaces from Synthetic Aperture Radar, Sensors, 8, 4213-4248, 2008.

Verstraeten, W. W., Veroustraete, F., van der Sande, C. J., Grootaers, I., and Feyen, J.: Soil moisture retrieval using thermal inertia, determined with visible and thermal spaceborne data, validated for European forests, Remote Sens. Environ., 101, 299-314, 2006.

Wagner, W., Lemoine, G., Borgeaud, M., and Rott, H.: A study of vegetation cover effects on ERS scatterometer data, IEEE T. Geosci. Remote, 37(2), 938-948, 1999a.

Wagner, W., Lemoine, G., and Rott, H.: A method for estimating soil moisture from ERS scatterometer and soil data, Remote Sens. Environ., 70(2), 191-207, 1999b.

Wagner, W., Scipal, K., Pathe, C., Gerten, D., Lucht, W., and Rudolf, B.: Evaluation of the agreement between the first global remotely sensed soil moisture data with model and precipitation data, J. Geophys. Res., 108(D19), 4611, doi:10.1029/2003JD003663, 2003.

Wagner, W. and Scipal, K.: Large-scale soil moisture mapping in Western Africa using the ERS scatterometer, IEEE T. Geosci. Remote, 38, 1777-1782, 2000.

Wagner, W.: Soil moisture retrieval from ERS Scatterometer Data, Ph.D. thesis, Vienna University of Technology, Austria, available at http://www.ipf.tuwien.ac.at/radar/ascat/publ/0015.pdf, 1998.

Western, A. W. and Blöschl, G.: On the spatial scaling of soil moisture, J. Hydrol., 217(3-4), 203-224, 1999.

Wösten, J. H. M., Lilly, A., Nemes, A., and Le Bas, C.: Development and use of a database of hydraulic properties of European soils, Geoderma, 90(3), 169-185, 1999. 